\section{ENERGY HUNGRY}

Researchers are trying to find targets within cancer's

metabolic cycles, such as one that breaks down glucose.
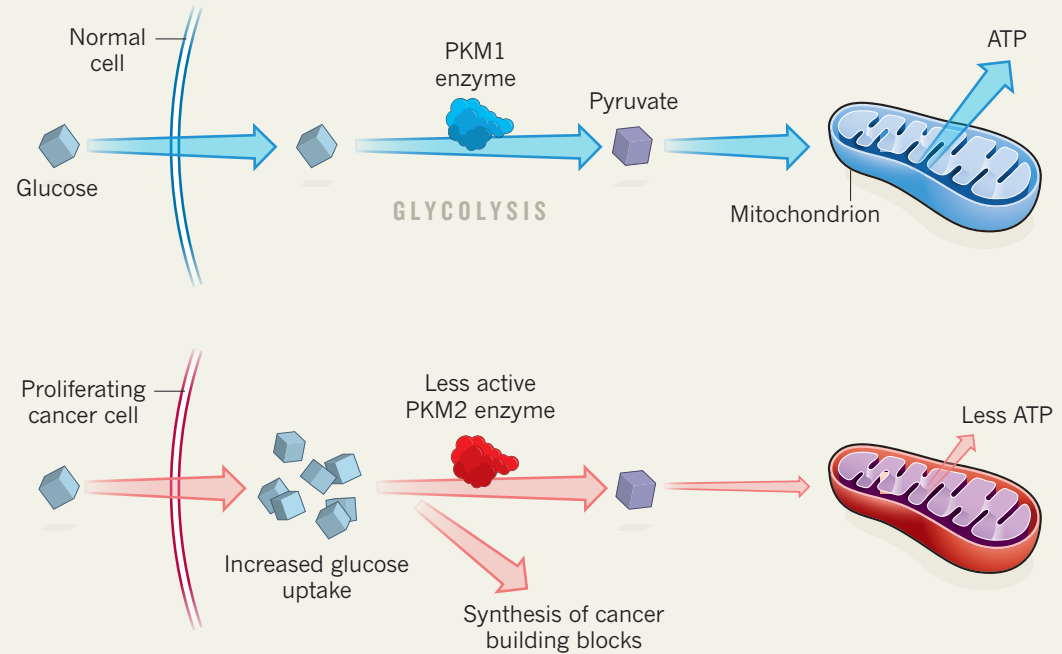

drug that blocks glutaminase, the enzyme that converts glutamine to glutamate, a key step in the cycle. The hope, says Calithera chief executive Susan Molineaux, is that because of cancer cells' strong dependence on glutamine, concentrations of the inhibitor can be found that will halt cancerous growth without damaging healthy cells.

But finding that sweet spot poses a challenge, because the metabolic oddities associated with cancer are sometimes found in normal cells that need to proliferate rapidly, such as immune cells. Agios was able to sidestep that hurdle by targeting an abnormal form of the IDH2 enzyme associated with cancer.

\section{ENZYME CONUNDRUM}

Other approaches have not had the benefit of such a clear target, and have suffered as a result. Several companies, including Agios, have studied an enzyme called pyruvate kinase that helps to break down glucose in the Warburg effect. Most normal cells produce a form of the enzyme called PKM1, but cancer cells tend to favour a less active form, PKM2. That pattern suggested that a drug blocking PKM2 could halt cancer growth.

But Vander Heiden and his colleagues found that tumours grew faster, not more slowly, in mice that lacked PKM2 (W. J. Israelsen et al. Cell 155, 397-409; 2013). To explain this strange result, the researchers hypothesize that multiplying cancer cells may prefer the less active PKM2 - or even no pyruvate kinase at all - because it allows glucose breakdown products to be shunted into pathways that generate molecules needed to build new cancer cells (see 'Energy hungry'). Although that would result in less ATP generated per molecule of glucose broken down, the cells can compensate by taking up more glucose. Nevertheless, the results cast doubt on PKM2 as a drug target. "Initially, people were very excited about PKM2," says Hay. "But then it turned out to be more complicated than expected."

Although Chandel is glad that cancermetabolism research is taking centre stage, he thinks that expectations for drugs based on the research might be too high - most attempts will not succeed. Even so, he adds, the fervour should lead to a better understanding of metabolic processes in both healthy and diseased cells. "These are good days for studying metabolism," he adds. "It's very interesting biology that's been neglected for over 30 years." -

\section{PUBLIC HEALTH}

\section{E-cigarettes affect cells}

\section{Questions raised over health effects of devices.}

\section{BY DANIEL CRESSEY}

$\mathrm{E}$ lectronic cigarettes can change gene expression in a similar way to tobacco, according to one of the first studies to investigate the biological effects of the devices.

Presented at the American Association for Cancer Research annual meeting on 6 April in San Diego, California, the research looked at human bronchial cells that contained some mutations found in smokers at risk of lung cancer. The cells were immortalized, grown in culture medium that had been exposed to e-cigarette vapour and their gene expression profiled.

The researchers found that the cells grown in medium exposed to the vapour of e-cigarettes showed a similar pattern of gene expression to those grown in a medium exposed to tobacco smoke (S. J. Park et al. Clin. Cancer Res. 20, B16; 2014).

The changes are not identical, says study researcher Avrum Spira, who works on genomics and lung cancer at Boston University in Massachusetts. But "there are some striking similarities", he says. The team is now evaluating whether the alterations mean that cells behave more like cancer cells in culture.

The work is at a very early stage and therefore cannot establish that e-cigarettes can cause cancer in vitro, let alone in vivo. "They may be safer [than tobacco], but our preliminary studies suggest that they may not be benign," says Spira.

E-cigarettes are extremely controversial. Because they vaporize liquid containing nicotine, rather than burning tobacco, some researchers believe that the devices could greatly reduce the damage done to health by smoking; others, however, argue that they are simply 'renormalizing' smoking.

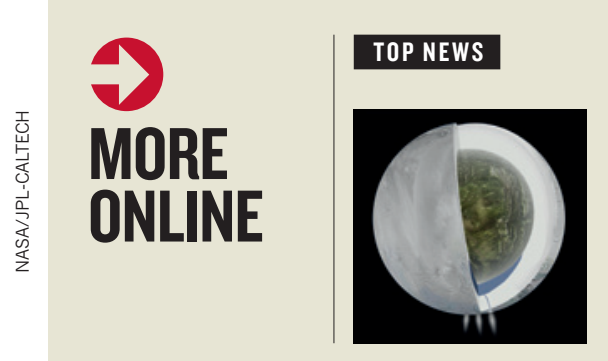

Saturn's moon Enceladus hides huge water ocean under its south pole go.nature. com/vijdmf

\section{MORE NEWS}

- Public disclosure leads to more retractions of flawed publications go.nature.com/rwos3y

- Europe urged to relax text-mining access go.nature.com/gndekt

- How Earth got its tectonic plates go.nature.com/715d6y

\section{NATURE PODCAST}

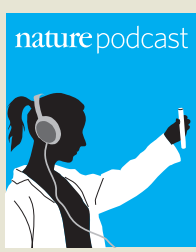

Flooding the Colorado River; being an IPCC contributor; and amoebae eating nature.com/nature/ podcast 